\title{
Reproductive effort affects subsequent horn growth in sexually dimorphic male ungulates
}

\author{
Christian Simon Willisch ${ }^{1}$ (ID $\cdot$ Peter Neuhaus $^{2}$
}

Received: 27 May 2020 / Accepted: 28 July 2021 / Published online: 1 September 2021

(c) The Author(s) 2021

\begin{abstract}
Trade-offs between reproductive effort and subsequent growth in males are not well explored, despite their relevance in questions of individual energy allocation. Regarding the growth of sexual secondary characters in polygynous breeding male mammals, indeed, no conclusive studies exist. We investigated in male Alpine ibex (Capra ibex) the relationship between their behavioral reproductive effort, current horn size, and subsequent horn growth. While controlling for age, no evidence was found for male behavioral reproductive effort during the rut being affected by their horn size. On the other hand, reproductive effort significantly decreased age-specific horn growth during the following summer. Our study provides evidence that growth of secondary sexual characters is traded against behavioral investments in reproduction in a male mammal. It bears important implications for the understanding of energy allocation between various life-history components and the evolutionary ecology of secondary sexual characters.
\end{abstract}

Keywords Energy allocation - Life-history $\cdot$ Reproductive behavior $\cdot$ Secondary sexual character $\cdot$ Somatic costs $\cdot$ Age $\cdot$ Horn growth

\section{Introduction}

The various life-histories of different organisms reflect the strategies individuals adopt to allocate their limited energetic resources to the different fitness components of an individual, such as growth, survival and reproduction. In its widest sense, energy allocation at any point in the life of an organism can be regarded as an investment into either current or future reproduction (Kozłowski 1992). Because reproduction is costly, the residual reproductive value of organisms will decline once they have started to breed (Pianka and Parker

Christian Simon Willisch

christian.willisch@bfh.ch

School of Agricultural, Forest and Food Sciences HAFL, Bern University of Applied Sciences, Länggasse 85, CH-3052 Zollikofen, Switzerland

2 Department of Biological Sciences, University of Calgary, 2500 University Dr. NW, T2N 1N4 Calgary, AB, Canada 
1975;Bell 1980). The 'decision' when and where to invest disposable energy is therefore crucial to all organisms (Stearns 1992). Interestingly, studies very often fail to present evidence for the expected trade-offs in energy allocation between different life history components. Instead, the various components are frequently found to be independent of each other or to covary positively (e.g., Bonenfant et al. 2009; Wilson and Nussey 2010), which is most likely due to variation in resource acquisition and allocation (Hamel et al. 2010). There are, thus, major individual differences in the efficiency with which energy and nutrients are assimilated by organisms, and in the way these resources are used.

In accordance with this argument, in long-lived, polygynous male ungulates, the size of horns and antlers is often positively correlated with survival and reproductive success (Bonenfant et al. 2009). The lack of any consistent trade-offs between the growth of a specific secondary sexual character, survival and reproduction, is mostly attributed to the overall quality of individuals: males are assumed to modulate their reproductive effort in accordance with the energy resources disposable to them (which themselves may vary individually from year to year, based on changing environmental conditions; Pettorelli et al. 2005; Parker et al. 2009). Animals with large energy resources, i.e. high-quality males, are therefore assumed to be able to devote more energy to reproduction than males with small energy resources (i.e. low-quality males), while still maintaining high survival and growth rates (Wilson and Nussey 2010) .

Regarding a potential trade-off between growth of secondary sexual characters and reproduction, studies in male ungulates typically have focused on the question whether reproduction is affected by the size of horns/antlers. Accordingly, there are numerous examples showing that male reproductive success in ungulates is usually increasing with horn/ antler size (e.g., Coltman et al. 2002; Kruuk et al. 2002; Willisch et al. 2015). On the other hand, studies investigating the effect of reproduction on subsequent growth of secondary sexual characters in male ungulates and other mammals are, to the best of our knowledge, still missing. Because secondary sexual characters are important determinants of reproductive success in polygynous male ungulates (Emlen 2008) and because energy allocation to reproduction during the mating season is pivotal in understanding the observed relationship among male life history components (Festa-Bianchet 2012; Lemaître et al. 2014), it is essential to know the potential effect of reproductive effort on the subsequent growth of horns and antlers.

For Alpine ibex, a sexually highly dimorphic mountain ungulate, previous research indicates that males may be suffering from increased reproductive costs via depressed future growth of horns (Willisch et al. 2015). However, explicit data linking reproductive effort during the mating season with subsequent horn growth is missing for this species. In order to deepen our understanding of secondary sexual characters and reproduction, we investigated in this study (i) to what extent the age-specific total horn length in male Alpine ibex is associated with their behavioral reproductive effort during the current mating season, and (ii) if the behavioral reproductive effort itself is influencing subsequent age-specific horn growth during the following summer. Considering that horn size in male Alpine ibex covaries positively with the genetic and phenotypic constitution of individuals (Bergeron et al. 2008; Brambilla et al. 2015; von Hardenberg et al. 2007), we expected for males of a given age, that individuals with longer horns would invest more time into the acquisition of mating partners during the rut, than individuals with shorter horns. Furthermore, we predicted that reproductive effort during the mating season would negatively affect age-specific horn 
growth during the following summer. Males being more reproductively active during the mating season were, consequently, predicted to experience higher somatic costs in terms of depressed subsequent horn growth than less reproductively active males.

\section{Materials and methods}

\section{Study animals}

The study was carried out in the Alpine ibex population 'Cape au Moine' north of Les Diablerets, Switzerland ( $46^{\circ} 22^{\prime}$ N, $07^{\circ} 09^{\prime}$ E; 1,700-2,550 m elevation). At the time of the study population size ranged between 220 and 270 animals (composed of 110-120 females, 80-95 males and 40-65 juveniles). Female Alpine ibex were permanently resident in the study area. Together with their offspring, they built groups of varying size from a few individuals up to about 50 animals. Males lived year-round in open, unstable fission-fusion societies, where individuals were free to join or leave groups. Some males roamed between this population and two adjacent populations. The composition of males during the rut varied therefore markedly from year to year (for details see Willisch and Neuhaus 2009).

\section{Life-history of Alpine ibex}

Alpine ibex are sexually dimorphic animals (Loison et al. 1999). Males are long-lived and enjoy high annual survival until 10-11 years of age (Toïgo et al. 2007). Asymptotic body size is normally not reached before the age of 8 years. Adult males possess impressively large horns that can exceed $1 \mathrm{~m}$ in length (Lüps et al. 2007). The production and also the carrying of horns are both assumed to be energetically costly (Festa-Bianchet et al. 2004; Toïgo et al. 2013). In line with that, annual horn growth varies positively with body mass (Bergeron et al. 2010), suggesting that horn growth is condition-dependent. Accordingly, environmental factors (e.g., onset of vegetation growth and springtime temperatures) are known to affect horn growth through the nutritional status of the animal (Giacometti et al. 2002; Büntgen et al. 2014). In male Alpine ibex, horn size is together with body mass an important determinant of dominance (Bergeron et al. 2010; Willisch et al. 2015), and dominance itself is the determining factor enabling males to obtain unrestricted access to receptive females during. However, reproductive success, is, in addition to age, positively related with horn size, in that, early-life horn growth significantly affects dominance and hence reproductive success, whereas horn growth later in life has no marked impact (Willisch et al. 2015). There are two mating tactics in Alpine ibex which are described in more detail below.

\section{Mating system}

The rut of Alpine ibex takes place under harsh environmental conditions in winter (i.e., snow, food shortage, freezing temperatures). In our study area, it typically starts during the first half of December and normally lasts 4-6 weeks until about mid-January. Although agonistic interactions between males are much reduced during the rut (Willisch and Neuhaus 2010), a high level of intra-male competition is apparent, as receptive females are showing a moderate temporal synchronization of estrus together with a patchy spatial dis- 
tribution (Willisch and Neuhaus 2009). Males try to get mating access to receptive females by using either of two dominance-based alternative mating tactics (Willisch and Neuhaus 2010). Dominant males adopt the primary tactic called 'tending'. Tending males monopolize access to single receptive females by following, courting, and defending them persistently against competitors. Subordinate males adopt a sneaking tactic, termed 'coursing'. They typically wait in the vicinity of a receptive female and her tending male, for any sudden temporary mating opportunity. The adoption of the two mating tactics is not fixed, and males can switch between the tactics depending on the dominance relationships they have with competing males in their vicinity. A male, using the tending tactic for getting access to a receptive female, will resort to the coursing tactic (or leave), as soon as a more dominant male is approaching. A subordinate, coursing male can, on the other hand, switch to 'tending' if the dominant male is leaving the female (Willisch and Neuhaus 2010). If a male is abandoning a receptive female, it does per definition not engage in any of the two tactics anymore. Observations have shown that copulations by tending males are by far more frequent than copulations by coursing males, because mating opportunities for coursing males are rare and only occur suddenly, when tended females start to run or when they move or stand too far away from the tending male (Willisch and Neuhaus 2009). These ensuing so-called 'coursing chases' may be less frequent with a lot of snow on the ground, suggesting that extreme environmental conditions can impact the use and effectiveness of the two alternative mating tactics (Apollonio et al. 2013). In our study population male reproductive success was heavily skewed towards old, dominant, tending males, while subordinate, young males resorted to the coursing tactic, with a much smaller chance of siring offspring (Willisch et al. 2012). It is worthwhile to note here, that male Alpine ibex, unlike some other ungulates (Willisch and Ingold 2007) still appear to maximize their energy intake by continuing the foraging and ruminating activity as much as possible during the rut (Brivio et al. 2010). Therefore, even while associating with receptive females (either by tending or coursing) males still forage, and thus likely minimize excessive mass loss during the rut.

\section{Data sampling}

Behavioral observations on nine marked and 45 individually recognizable (by unique characteristics of their horns and coat coloration; see Willisch and Neuhaus 2009) male Alpine ibex were conducted, using spotting scopes during three rutting seasons in December/January of 2005-2006, 2006-2007 and 2007-2008. For the present study we only considered observations that took place during peak rut, which was defined each year, based on the date of the first defended, receptive female, and then lasted for the following 5 weeks (for details see Willisch and Neuhaus 2009).

Continuous focal animal sampling (Altmann 1974) was used to obtain data on the proportion of time individual males spent in different behaviors. Each day, observers selected between 1 and 3 focal animals and observed them continuously, resulting in $578 \mathrm{~h}$ of 120 continuous focal observations $(4.8 \pm 2.2 \mathrm{~h}$, mean $\pm \mathrm{SD})$ of a total of 54 different males. Observers tried to distribute observations equally over all individuals and age classes. To accomplish this, detailed accounts of all focal observations were kept, and observers always decided, in advance, which individuals were to be chosen as focal animals each day. Recorded behaviors included feeding, ruminating, standing, moving (walking and running), courtship and agonistic behavior. The courtship behavior was composed of all female-ori- 
ented displays such as low-stretch, tongue-flick, sniff, lick, flehmen, touch, self-stimulation, scent-urination, mount attempt, mount, and copulation. Agonistic behaviors included activities and displays directed to male conspecifics like evasion and flight in response to an approaching male, displacement or chase of another male, rush towards another male, horn contact/clash and homosexual mount (Willisch and Neuhaus 2009, 2010). These behaviors were displayed by all males irrespective of whether they adopted an alternative mating tactic (i.e., tending or coursing) or not (i.e., in situation where males were not associating with a receptive female). To quantify the use of the two mating tactics the duration of all tending and coursing bouts for each male were noted. A tending bout started when a dominant male began to defend and monopolize access to a receptive female against subordinate competitors, and ended when he left the receptive female, or lost his tending position to another more dominant male. A coursing bout, on the other hand, started when a subordinate male began to associate with a receptive female that was already defended by a tending male and it ended when the coursing male left the tended female, or when he was able to inherit the tending position from the dominant male, if the latter abandoned the female (Willisch and Neuhaus 2009, 2010). When males did not associate with a receptive female, they were judged of having adopted neither tactic. We considered reproductive effort (costs) to be increased in males allocating less time to feeding and ruminating (taken together, as in ruminants the process of energy-acquisition is composed of these two activities), and more time in energy-consuming activities, such as standing, moving, courtship behaviors, agonistic behaviors plus the usage of alternative mating tactics. For the analyses we extracted from each focal observation the proportions of time individual males allocated to the different behaviors and tactics and then averaged theses values for each male and year. A detailed description of the age-dependent allocation of time to the various behaviours and mating tactics is provided in the supplementary material.

Annual horn increments of captured and marked individuals $(\mathrm{N}=29)$ and unmarked animals shot $(\mathrm{N}=17)$ or found dead $(\mathrm{N}=3)$ were determined using measuring tape and scaled photographs. In addition, horn increments of free-ranging unmarked males $(\mathrm{N}=58)$ were multiply estimated ( $\leq 8$ times) by the photogrammetric approach described in Willisch et al. (2013). In total, we successfully collected horn measurements of 107 different individuals. A detailed quantitative description of the age-dependent horn growth pattern is presented in the supplementary material.

As mentioned above, total horn length is likely to reflect the genetic and phenotypic quality of individuals. To investigate the influence of horn size on the behavioral time investments during the rut we considered for every individual its total horn length. In our study, total horn length $(\mathrm{TH})$ was the summed-up length of all horn annuli with exception of the one produced as kid (referred to as annulus ' 0 '). This annulus was omitted because it becomes worn out as males are getting older. For the analyses we then used for each male its relative deviance from the mean age-specific horn length $(\mathrm{RDH})$. This measure was calculated as follows: $\mathrm{RDH}=(\mathrm{TH}-\mathrm{MH}) / \mathrm{MH}$, where $\mathrm{TH}=$ total horn length, $\mathrm{MH}=$ mean age-specific horn length of all males. MH was extracted from a 2nd order polynomial regression curve fitted to the horn length data, using age as a predictor (see supplementary material, Willisch et al. 2015). By doing so, the relative differences in the age-specific horn lengths became comparable across age classes. Accordingly, a positive RDH value indicates that the individual age-specific horn length is above the average horn length for that age in the population, whereas a negative RDH value indicates that individual horn length is below the average. 
To evaluate the potential influence of a male's behavior during the rut on his subsequent horn growth, we considered the length of the horn annulus grown during the year following the rut (HA). We then calculated for each male the relative deviance from the mean agespecific horn annulus length $(\mathrm{RDA}): \mathrm{RDA}=(\mathrm{HA}-\mathrm{MA}) / \mathrm{MA}$, where $\mathrm{MA}=$ the mean horn annulus length produced at a given age based on the data of all males, and HA=is a male's horn growth after the rut. Thus, differences in annual horn growth became directly comparable across age-classes. Hence, a positive RDA value indicates that the individual horn annulus length at a given age is above the average horn annulus length for this age class in the population, whereas a negative RDA value indicates that the horn annulus length is below the average.

Overall, horn measurements with associated behavioral data were available for 40 different males. While all 40 males were used for the analyses regarding the impact of agespecific total horn length on the behavior during the current rut (corresponding to a total of $478 \mathrm{~h}$ of focal observations), we only had data for 28 males for whom we had both their behavior during the rut, and measures of age-specific horn growth in the subsequent summer (corresponding to a total of $318 \mathrm{~h}$ of focal observations). For these latter analyses, only a subset of males could be considered because subsequent horn growth in the year following the rut could not be determined for all 40 individuals.

All aspects of animal capture and data collection were approved by the Swiss Federal Office of the Environment (FOEN) and the Swiss Federal veterinary office (FVO) and conformed to the guidelines for ethical treatment of animals.

\section{Statistical analyses}

Statistical analyses were performed in R (version 3.5.1, R Development Core Team 2018). We applied linear mixed-effects models (Pinheiro and Bates 2000) using the R package 'nmle'. The proportion of time males spent in the various activities/or tactics were arcsine square-root-transformed to approximate normal distributions (Zar 1999).

We tested the influence of individual residual total horn length (RDH) on the (transformed) proportion of time spent in various behaviors (i.e., feeding and ruminating, moving, standing, courtship behaviors and agonistic behaviors) and mating tactics (i.e., tending and coursing, respectively) during the rut with RHD as fixed effect and observation year, age of male, and animal ID as random effects.

To determine the effects of different behaviors and the adoption of mating tactics during the rut on the subsequent horn annulus growth, we also ran linear mixed-effects models with behavioral categories and mating tactics, respectively, as fixed effect factors, and year of observation, male age, and animal ID as random factors. For the evaluation of the influence of the different behaviors, displayed by males during the rut, on subsequent horn growth, we applied a stepwise backward regression. In this case, we were using linear mixed-effects models based on the ML estimation (instead of the estimation by REML used in the other models) to be able to compare different models: Starting with the full model, containing all behavioral categories in each step the behavior with the least significant term was eliminated from the model. We used the Akaike Information Criterion (AIC) to choose among competing models. A model was considered to outperform another when its AIC value was $\geq 2$ units smaller. When AIC differences were $<2$ the more parsimonious model was selected (Crawley 2007). 


\section{Results}

\section{Association between total horn length and behavior during the rut}

Controlling for year of observation, animal ID, and animal age (i.e., to remove age effects) linear mixed-effects models (based on 40 males for which behavioral data during at least one rut and the corresponding horn measurements in that year were available; $\mathrm{N}_{\text {total }}=49$ ) showed that relative age-specific horn lengths $(\mathrm{RDH})$ had no effect on the proportion of time individuals allocated to the various behaviors (feeding and ruminating: estimate $=0.21 \pm 0.22$, d.f. $=21$, $\mathrm{t}$-value $=0.94, \mathrm{p}=0.36$; moving: estimate $=0.017 \pm 0.105$, d.f. $=21$, $\mathrm{t}$-value $=0.16$, $\mathrm{p}=0.87$; standing: estimate $=-0.23 \pm 0.18$, d.f. $=21$, $\mathrm{t}$-value $=-1.28, \mathrm{p}=0.21$; agonistic behavior: estimate $=-0.001 \pm 0.049$, d.f. $=21$, $\mathrm{t}$-value $=-0.03, \mathrm{p}=0.98$; or courtship behavior: estimate $=-0.017 \pm 0.244$, d.f. $=21$, t-value $=-0.07, \mathrm{p}=0.95)$.

The proportion of time males $\left(\mathrm{N}_{\text {males }}=39\right.$ of $\left.\mathrm{N}_{\text {total }}=46\right)$ engaged in alternative mating tactics (i.e., tending or coursing) during the rut did not depend on their age-specific horn lengths $(\mathrm{RDH})$ either (estimate $=-0.65 \pm 0.56$, d.f. $=21$, $\mathrm{t}$-value $=-1.16, \mathrm{p}=0.26$ ). Also, when young and old males were analyzed separately, no significant effect of RDH on the proportion of time spent coursing or tending, was detected (coursing in 2-5 years old males $\left(\mathrm{N}_{\text {total }}=14, \mathrm{~N}_{\text {males }}=14\right)$ : estimate $=0.04 \pm 1.36$, d.f. $=4$, t-value $=0.03, \mathrm{p}=0.98$; tending in males $\geq 7$ years old $\left(\mathrm{N}_{\text {total }}=25, \mathrm{~N}_{\text {males }}=22\right)$ : estimate $=0.53 \pm 0.62$, d.f. $=11$, $\mathrm{t}$-value $=0.86$, $\mathrm{p}=0.41)$.

\section{Influence of behavior during the rut on subsequent horn growth}

Stepwise elimination of non-significant terms (see supplementary material) revealed that the relative age-specific lengths of the horn annuli (RDA) were positively correlated with the time allocated to feeding and ruminating in the preceding rut (Fig. 1), as the best mixed-
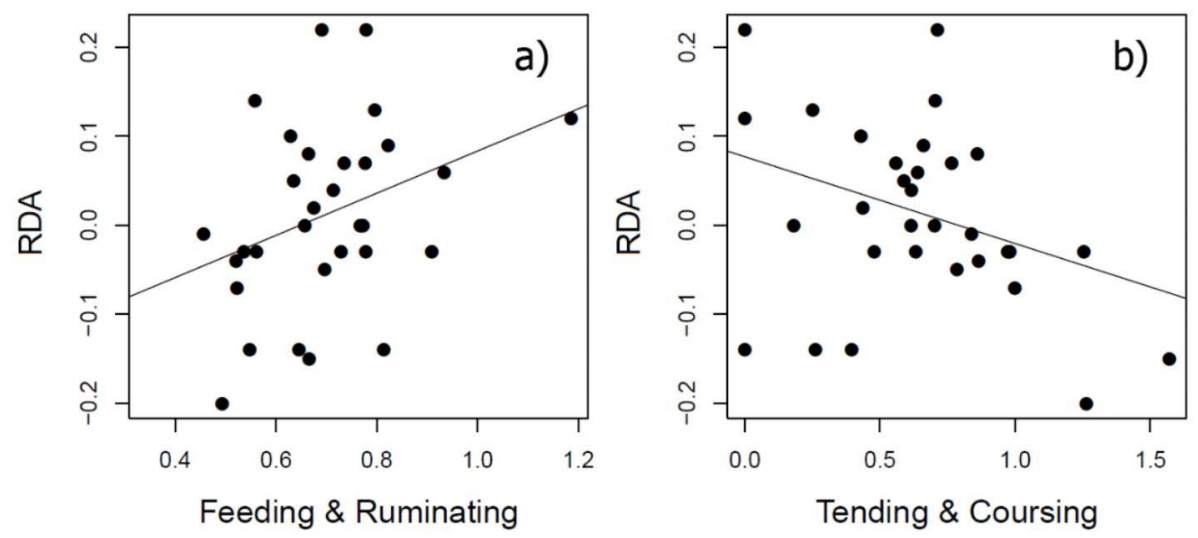

Fig. 1 Relationship between the relative deviance from the mean age-specific horn annulus length $(R D A)$ grown during the summer after the rut and the arcsine-square-root-transformed proportion of time male Alpine ibex allocated to (a) feeding and ruminating, and (b) tending and coursing. Regression lines are based on the parameter estimates of the corresponding linear mixed-effects models (see text for details). 
effects model (with year of observation, male age, and animal ID as random factors) only contained the proportion of time spent feeding and ruminating as explanatory variable for the RDA (estimate $=0.24 \pm 0.10$, d.f. $=12$, $\mathrm{t}$-value $=2.36, \mathrm{p}=0.036 ; \mathrm{N}_{\text {males }}=28, \mathrm{~N}_{\text {total }}=31$ ). No significant effects were detected for the proportions of time allocated to moving, standing, agonistic and courtship behavior during the rut (for all $\mathrm{p}>0.05$ ).

Relative age-specific annual horn growth (RDA) during the summer was, furthermore, negatively influenced by the proportion of time males were allocating to either tending or coursing during the preceding rut (estimate $=-0.10 \pm 0.05$, d.f. $=12$, t-value $=-2.14$, $\mathrm{p}=0.05 ; \mathrm{N}_{\text {males }}=28, \mathrm{~N}_{\text {total }}=31 ;$ Fig. 1). Hence, males engaging more in alternative mating tactics during the rut showed a reduced horn growth during the following summer compared to males engaging less in alternative mating tactics.

\section{Discussion}

Contrary to our prediction, the various behaviors and the adoption of alternative mating tactics during the rut were not affected by an individual's total horn length. Hence, there is no indication that male Alpine ibex are modulating their reproductive effort in terms of time invested into energetically costly activities (such as moving, courting, agonistic behavior or mating tactics) or the reduction of activities for the acquisition of energy (i.e., feeding and ruminating) with respect to differences in age-specific total horn length. On the other hand, we demonstrate that age-specific annual horn growth varies with the behavior of males during the preceding rut, something recently suggested in a theoretical paper using bighorn sheep (Ovis canadensis) as model species (Schindler et al. 2020). Particularly, we found a positive impact of the proportion of time males allocated to feeding and ruminating during the preceding rut on their horn growth the following year. In Addition, we saw that active participation in mating activities (coursing or tending) resulted in reduced subsequent horn growth as well. Accordingly, this is the first empirical study to use data on both behavior and horn growth to show a direct impact of male rutting behavior on subsequent growth of a secondary sexual characters in a wild mammal population.

\section{Reproductive effort as a function of horn size}

Interestingly, no evidence was found that relatively large-horned male Alpine ibex would invest more time into reproduction than relatively short-horned individuals of a given age. Our results, therefore, suggest that investments into reproduction during the rut do not vary with the genetic and phenotypic quality of individuals (for which horn length was taken as an indicator; Bergeron et al. 2008; von Hardenberg et al. 2007). Instead reproductive effort appears to increase mainly with male age (see supplementary material), as is often the case in ungulates (Mysterud et al. 2004), and which has also previously been demonstrated for Alpine ibex (Willisch and Neuhaus 2009; Brivio et al. 2010).

Nevertheless, we have to acknowledge that a male's behavioral or mating effort might still vary with his current body condition, even if it is not varying with the overall constitution of individuals for which horn size is an indicator (von Hardenberg et al. 2007). Although body mass and horn growth are typically correlated with each other (Bergeron et al. 2010), actual body condition could have a direct effect on the behavioral investments 
during the rut. Because we do not have estimates for body mass, we cannot rule out that in male Alpine ibex behavioral effort during the rut might, in addition to age, also depend on their current body condition. Examples demonstrating a positive relationship between body mass and reproductive effort exist at least for some other polygynous male ungulates. In mountain goats (Oreamnos americanus), for instance, pre-rut body mass was shown to positively affect courtship-behavior during the rut (Mainguy and Côté 2008), and pre-rut body mass was also positively associated with time spent in rutting activities by young bighorn rams (Pelletier 2005).

Considering that horn size has recently been shown to have a significant positive effect on male dominance and reproductive success in male Alpine ibex (Willisch et al. 2015), the lack of any positive relationship between behavioral effort during the rut and the agespecific size of horns is very intriguing. It implies that males with comparably long horns for their age, i.e., high-quality males, are not investing more time, and thus energy during the rut than relatively short-horned males of the same age. However, males with longer horns are achieving a higher social status translating into bigger reproductive success.

High-quality males, therefore, appear to be more efficient in the successful conversion of time and energy investments during the rut than low-quality males. Our results suggest that reproductive effort during the rut and reproductive reward are not directly linked in male Alpine ibex. This finding is in line with a previous study showing a similar pattern in fallow deer (McElligott et al. 2003). Because access to receptive females is a function of male social status (Willisch and Neuhaus 2010), intra-male competitiveness is the main factor limiting reproductive success in male Alpine ibex (Willisch et al. 2012). Since social relationships among males are to a considerable extent established before the actual mating season, the dominance-based mating system of Alpine ibex enables full-grown largehorned, i.e., high-quality males, to easily gain mating access to receptive females during the rut. Indeed, previous observations confirm that dominant males can monopolize access to receptive females without effort, as subordinate males walk away from a female and stay at distance as soon as a more dominant individual approaches (Willisch and Neuhaus 2009, 2010). Whether the establishment of social relationships among competing males during the pre-rut season is a direct function of the presence of competitors in the area, as suspected by Festa-Bianchet (2012), and whether high-quality males are incurring higher costs (Bergeron et al. 2008; Toïgo et al. 2013), at least during that period of the year, remains open.

\section{Horn growth as a function of reproductive effort}

There are numerous studies evaluating the effects of reproduction on growth in females. For long-lived ungulates, for example female reproductive effort is known to result in reduced horn growth (Miura et al. 1987; Coté et al. 1998) and body condition (Green and Rothstein 1991). The absence of studies showing a direct effect of reproductive effort on subsequent growth in males is astonishing. Despite its relevance (Simmons and Kotiaho 2007) only few studies have so far evaluated such trade-offs. In fish, for instance, it has been shown that male reproductive effort results in reduced growth (Lindström 2001; Jordan and Brooks 2010), while no negative effects were detected in snakes (Brown and Weatherhead 2004). For male ungulates evidence linking reproductive effort and growth is still largely lacking. Since reproductive effort and horn/antler growth are separated by months, it is unclear if investments into reproduction are effectively leading to a reduced horn growth. 
To our knowledge, the only scientific account providing some information on this relationship is based on records of captive animals. In the mentioned study the current antler size of male red deer was unrelated to the mass loss during the preceding mating season suggesting that the growth of antlers is not affected by male reproductive effort (Gaspar-López et al. 2010). However, because of supplemental feeding in captivity and the absence of competitors, the energetics of captive animals are likely fundamentally different from those of free-living wild animals, such that the results of this latter study may not be conclusive (Hoefs and Nowlan 1997).

In summary, our study offers completely novel insights into the link between immediate reproductive effort and subsequent horn growth in a male ungulate species. Although a trade-off between reproductive investments during the rut and age-specific horn growth could be expected, discovering such a direct effect of reproduction-related activities on horn growth in the following year is of fundamental importance for our understanding of the reproductive ecology of sexually dimorphic polygynous male ungulates. While the models by Schindler et al. (2020) supported such a theoretical trade-off in bighorn sheep, actual empirical data have not been presented for any ungulate species so far. Hence, our results provide the first empirical evidence that reproductive effort may generate non-negligible somatic costs to individual male ungulates which may impair future fitness prospects over the long-term, by limiting the growth of horns. Because horn size is an important secondary sexual character that is positively related to male reproductive success (Willisch et al. 2015), individual male Alpine ibex are facing a trade-off between current and future reproduction. Consequently, during each mating season they must carefully invest the available energy resources to maximize, not only the current, but via horn growth, also their future reproductive success.

Considering that in other ungulates males are also investing considerable time and energy into the acquisition of female mating partners (Mysterud et al. 2004), it would be interesting to see whether in these species the growth of horns/antlers is also depending on the preceding rut's behavioral reproductive effort. Taking male ungulates as models can help to greatly deepen our understanding of how the critical trade-offs in energy allocation to the growth of secondary sexual characters, versus current investment into mating success and other lifehistory components are linked.

Supplementary Information The online version contains supplementary material available at https://doi. org/10.1007/s10682-021-10128-7.

Acknowledgements We thank J.-C. Roch, M.-P. Ryser-Degiorgis, N. Marreros, K. Bieri Willisch, P. Decristophoris, P. Deleury, I. Glanzmann, N. Grandjean, C. Hebeisen, B. Hofer, I. Leathwood, H. Nimmervoll, B. Nussberger, C. Wittker, M. Pewsner, and numerous volunteers for their help with captures and data collection. We are particularly grateful to K. Ruckstuhl for constructive comments on the manuscript and her statistical support. Also, we want to acknowledge the helpful comments of the editor and the anonymous referees on earlier drafts of this manuscript. Many thanks go to the authorities of the Canton Vaud and the Swiss Federal Office of the Environment FOEN.

Authors' contributions CSW and PN both conceived the study. CSW collected the behavioral data and the photographs, performed the photogrammetric and statistical analyses, and wrote the first draft of the manuscript. PN contributed to subsequent and final version(s) of the manuscript.

Funding Open Access funding provided by Berner Fachhochschule BFH. 
Availability of data and material (data transparency) The datasets generated during and analysed during the current study are available from the corresponding author on reasonable request.

\section{Declarations}

Ethics approval All aspects of animal capture and data collection were approved by the Swiss Federal Office of the Environment (FOEN) and the Swiss Federal veterinary office (FVO) and conformed to the guidelines for ethical treatment of animals.

Open Access This article is licensed under a Creative Commons Attribution 4.0 International License, which permits use, sharing, adaptation, distribution and reproduction in any medium or format, as long as you give appropriate credit to the original author(s) and the source, provide a link to the Creative Commons licence, and indicate if changes were made. The images or other third party material in this article are included in the article's Creative Commons licence, unless indicated otherwise in a credit line to the material. If material is not included in the article's Creative Commons licence and your intended use is not permitted by statutory regulation or exceeds the permitted use, you will need to obtain permission directly from the copyright holder. To view a copy of this licence, visit http://creativecommons.org/licenses/by/4.0/.

\section{References}

Altmann J (1974) Observational study of behavior - Sampling methods. Behavior 49:227-267

Apollonio M, Brivio F, Rossi I et al (2013) Consequences of snowy winters on male mating strategies and reproduction in a mountain ungulate. Behavioural Processes 98:44-50. doi: https://doi.org/10.1016/j. beproc. 2013.05 .001

Bell G (1980) The costs of reproduction and their consequences. Am Nat 116:45-76

Bergeron P, Festa-Bianchet M, Von Hardenberg A, Bassano B (2008) Heterogeneity in male horn growth and longevity in a highly sexually dimorphic ungulate. Oikos 117:77-82. doi:https://doi. org/10.1111/j.2007.0030-1299.16158.x

Bergeron P, Grignolio S, Apollonio M et al (2010) Secondary sexual characters signal fighting ability and determine social rank in Alpine ibex (Capra ibex). Behav Ecol Sociobiol 64:1299-1307. doi:https://doi. org/10.1007/s00265-010-0944-x

Bonenfant C, Pelletier F, Garel M, Bergeron P (2009) Age-dependent relationship between horn growth and survival in wild sheep. J Anim Ecol 78:161-171. doi:https://doi.org/10.1111/j.1365-2656.2008.01477.x

Brambilla A, Biebach I, Bassano B et al (2015) Direct and indirect causal effects of heterozygosity on fitnessrelated traits in Alpine ibex. Proceedings of the Royal Society B: Biological Sciences 282:20141873. doi: https://doi.org/10.1098/rspb.2014.1873

Brivio F, Grignolio S, Apollonio M (2010) To feed or not to feed? Testing different hypotheses on rut-induced hypophagia in a Mountain Ungulate. Ethology 116:406-415. doi:https://doi. org/10.1111/j.1439-0310.2010.01753.x

Brown GP, Weatherhead PJ (2004) Sexual abstinence and the cost of reproduction in adult male water snakes, Nerodia sipedon. Oikos 104:269-276. doi:https://doi.org/10.1111/j.0030-1299.2004.12712.x

Büntgen U, Liebhold A, Jenny H et al (2014) European springtime temperature synchronises ibex horn growth across the eastern Swiss Alps. Ecol Lett 17:303-313. doi:https://doi.org/10.1111/ele.12231

Coltman DW, Festa-Bianchet M, Jorgenson JT, Strobeck C (2002) Age-dependent sexual selection in bighorn rams. Proceedings of the Royal Society B: Biological Sciences 269:165-172. doi: https://doi. org/10.1098/rspb.2001.1851

Coté SD, Festa-Bianchet M, Smith KG (1998) Horn Growth in Mountain Goats (Oreamnos americanus). J Mamm 79:406-414

Crawley MJ (2007) The R Book. John Wiley \& Sons Ltd, Chichester

Emlen DJ (2008) The evolution of animal weapons. Annu Rev Ecol Evol Syst 39:387-413. doi:https://doi. org/10.1146/annurev.ecolsys.39.110707.173502

Festa-Bianchet M (2012) The cost of trying: weak interspecific correlations among life-history components in male ungulates. Can J Zool 90:1072-1085. doi:https://doi.org/10.1139/z2012-080

Festa-Bianchet M, Coltman DW, Turelli L, Jorgenson JT (2004) Relative allocation to horn and body growth in bighorn rams varies with resource availability. Behav Ecol 15:305-312. doi:https://doi.org/10.1093/ beheco/arh014 
Gaspar-López E, Landete-Castillejos T, Estevez JA et al (2010) Biometrics, testosterone, cortisol and antler growth cycle in iberian red deer stags (Cervus elaphus hispanicus). Reprod Domest Anim 45:243-249. doi:https://doi.org/10.1111/j.1439-0531.2008.01271.x

Giacometti M, Willing R, Defila C (2002) Ambient temperature in spring affects horn growth in male Alpine ibexes. J Mammal 83:245-251

Green WCH, Rothstein A (1991) Trade-offs between growth and reproduction in female bisons. Oecologia $86: 521-527$

Hamel S, Gaillard JM, Yoccoz NG et al (2010) Fitness costs of reproduction depend on life speed: Empirical evidence from mammalian populations. Ecol Lett 13:915-935. doi:https://doi. org/10.1111/j.1461-0248.2010.01478.x

Hoefs M, Nowlan U (1997) Comparison of horn growth in captive and free-ranging Dall's rams. Journal of Wildlife Management 61:1154-1160

Jordan LA, Brooks RC (2010) The lifetime costs of increased male reproductive effort: Courtship, copulation and the Coolidge effect. J Evol Biol 23:2403-2409. doi:https://doi.org/10.1111/j.1420-9101.2010.02104.x

Kozłowski J (1992) Optimal allocation of resources to growth and reproduction: Implications for age and size at maturity. Trends Ecol Evol 7:15-19

Kruuk EB, Slate J, Pemberton JM et al (2002) Antler size in red deer: heritability and selection but no evolution. Evolution 56:1683-1695. doi:https://doi.org/10.1111/j.0014-3820.2002.tb01480.x

Lemaître J-F, Gaillard J-M, Pemberton JM et al (2014) Early life expenditure in sexual competition is associated with increased reproductive senescence in male red deer. Proceedings Biological sciences/The Royal Society 281:20140792-. doi: https://doi.org/10.1098/rspb.2014.0792

Lindström K (2001) Effects of resource distribution on sexual selection and the cost of reproduction in sandgobies. Am Nat 158:64-74. doi:https://doi.org/10.1086/320867

Loison A, Gaillard J-M, Pélabon C, Yoccoz NG (1999) What factors shape sexual size dimorphism in ungulates. Evol Ecol Res 1:611-633

Lüps P, Blöchlinger B, Schmid P, Zuber M (2007) Ontogenese und Variabilität verschiedener Körpermerkmale des Steinwildes Capra i. ibex im Berner Oberland (Schweizer Alpen). Beiträge zur Jagd- Wildforschung 32:495-510

Mainguy J, Côté SD (2008) Age- and state-dependent reproductive effort in male mountain goats, Oreamnos americanus. Behav Ecol Sociobiol 62:935-943. doi:https://doi.org/10.1007/s00265-007-0517-9

McElligott AG, Naulty F, Clarke WV, Hayden TJ (2003) The somatic cost of reproduction: what determines reproductive effort in prime-age fallow buck? Evol Ecol Res 5:1239-1250

Miura S, Kita I, Sugimura M (1987) Horn growth and reproductive history in female Japanese serow. J Mammal 68:826-836. doi:https://doi.org/10.2307/1381560

Mysterud A, Langvatn R, Stenseth NC (2004) Patterns of reproductive effort in male ungulates. J Zool 264:209-215. doi:https://doi.org/10.1017/S0952836904005618

Parker KL, Barboza PS, Gillingham MP (2009) Nutrition integrates environmental responses of ungulates. Funct Ecol 23:57-69. doi:https://doi.org/10.1111/j.1365-2435.2009.01528.x

Pelletier F (2005) Foraging time of rutting bighorn rams varies with individual behavior, not mating tactic. Behav Ecol 16:280-285. doi:https://doi.org/10.1093/beheco/arh162

Pettorelli N, Mysterud A, Yoccoz NG et al (2005) Importance of climatological downscaling and plant phenology for red deer in heterogeneous landscapes. Proceedings of the Royal Society B: Biological Sciences 272:2357-2364. doi: https://doi.org/10.1098/rspb.2005.3218

Pianka ER, Parker WS (1975) Age-Specific Reproductive Tactics. Am Nat 109:453-464

Pinheiro JC, Bates DM (2000) Mixed-effects models in S-Plus. Springer Verlag, New York

Schindler S, Ruckstuhl KE, Neuhaus P (2020) Male mating behaviour affects growth of secondary sexual traits: a mechanism for rapid phenotypic change. Anim Behav 169:129-138

Simmons LW, Kotiaho JS (2007) The effects of reproduction on courtship, fertility and longevity within and between alternative male mating tactics of the horned beetle, Onthophagus binodis. J Evol Biol 20:488-495. doi:https://doi.org/10.1111/j.1420-9101.2006.01274.x

Stearns SC (1992) The evolution of life histories. Oxford University Press, New York

Toïgo C, Gaillard JM, Festa-Bianchet M et al (2007) Sex- and age-specific survival of the highly dimorphic Alpine ibex: Evidence for a conservative life-history tactic. J Anim Ecol 76:679-686. doi:https://doi. org/10.1111/j.1365-2656.2007.01254.x

Toïgo C, Gaillard JM, Loison A (2013) Alpine ibex males grow large horns at no survival cost for most of their lifetime. Oecologia 173:1261-1269. doi:https://doi.org/10.1007/s00442-013-2700-1

Von Hardenberg A, Bassano B, Festa-Bianchet M et al (2007) Age-dependent genetic effects on a secondary sexual trait in male Alpine ibex, Capra ibex. Mol Ecol 16:1969-1980. doi:https://doi. org/10.1111/j.1365-294X.2006.03221.x

Willisch CS, Ingold P (2007) Feeding or resting? The strategy of rutting male Alpine chamois. Ethology 113:97-104. doi:https://doi.org/10.1111/j.1439-0310.2006.01301.x 
Willisch CS, Neuhaus P (2009) Alternative mating tactics and their impact on survival in adult male Alpine ibex (Capra ibex ibex). J Mammal 90:1421-1430. doi:https://doi.org/10.1644/08-MAMM-A-316R1.1

Willisch CS, Neuhaus P (2010) Social dominance and conflict reduction in rutting male Alpine ibex, Capra ibex. Behav Ecol 21:372-380. doi:https://doi.org/10.1093/beheco/arp200

Willisch CS, Biebach I, Koller U et al (2012) Male reproductive pattern in a polygynous ungulate with a slow life-history: The role of age, social status and alternative mating tactics. Evol Ecol 26:187-206. doi:https://doi.org/10.1007/s10682-011-9486-6

Willisch CS, Marreros N, Neuhaus P (2013) Long-distance photogrammetric trait estimation in free-ranging animals: A new approach. Mammalian Biology 78:351-355

Willisch CS, Biebach I, Marreros N et al (2015) Horn growth and reproduction in a long-lived male mammal: No compensation for poor early-life horn growth. Evol Biol 42:1-11. doi:https://doi.org/10.1007/ s11692-014-9294-3

Wilson AJ, Nussey DH (2010) What is individual quality? An evolutionary perspective. Trends in Ecology Evolution 25:207-214. doi:https://doi.org/10.1016/j.tree.2009.10.002

Zar JH (1999) Biostatistical analysis, 4th edn. Prentice-Hall, London

Publisher's Note Springer Nature remains neutral with regard to jurisdictional claims in published maps and institutional affiliations. 